\title{
DEMANDAS ESTRUTURAIS: FLEXIBILIDADE E GESTÃO
}

\author{
STRUCTURAL DEMANDS: FLEXIBILITY AND \\ MANAGEMENT
}

\begin{abstract}
ANTÔNIO CÉSAR BOCHENEK
Docente permanente do PPGPD/Enfam. Juiz federal do TRF4. Doutor em direito pela Universidade de Coimbra - Portugal. Mestre pela PUCPR.

https://orcid.org/0000-0001-6173-9368
\end{abstract}

\section{RESUMO}

O protagonismo dos tribunais e a insuficiência da atuação dos poderes constituídos transferem ao Judiciário os debates a respeito da efetividade ou omissão das políticas públicas. O Judiciário recebe demandas com estados de desconformidade dos direitos constitucionais, por meio dos litígios estruturais. Contudo, para o tema, ainda não há legislação processual específica, e são poucas as experiências empíricas estudadas. A pesquisa explora preceitos e valores do processo estrutural mediante interpretação e adaptação das normas existentes, em especial do Código de Processo Civil, que relativizam e mitigam a rigidez das regras processuais. Assim, a investigação centra-se nas duas características essenciais dos processos estruturais, isto é, a flexibilidade processual e a gestão judicial. Em contrapartida, decorrem novas funções judiciais. As pistas estão sendo lançadas para novas pesquisas e investigações.

Palavras-chave: demanda estrutural; processo estrutural; flexibilidade; gestão judicial; políticas públicas.

\section{ABSTRACT}

The role of the courts and the insufficient performance of the constituted powers, transfers to the judiciary the debates regarding the effectiveness or omission of public policies. The judiciary receives demands with states of non-conformity of constitutional rights, through structural disputes. However, for the topic there is still no specific procedural legislation and there are few empirical experiences studied. The research explores the 
precepts and values of the structural process through the interpretation and adaptation of existing norms, in particular, the Civil Procedure Code, which relativize and mitigate the rigidity of procedural rules. Thus, the investigation focuses on the two essential characteristics of structural processes, that is, procedural flexibility and judicial management. On the other hand, new judicial functions are taking place. Clues are being launched for further research and investigation.

Keywords: structural demand; structural process; dlexibility; fudicial management; public policy.

Recebido: 24-5-2021

Aprovado: 28-6-2021

A complexidade das relações sociais e jurídicas não é uma novidade, e a velocidade das mutações nas sociedades contemporâneas é progressiva e intensa. Nesse cenário, em constante e acelerada metamorfose, os representantes dos poderes constituídos precisam ter sensibilidade apurada para atender a todos os reclamos, interesses e direitos. Em meio a tantos pontos intrincados das relações entre os poderes constituídos e a sociedade, destaca-se que o Legislativo, que trabalha com a lógica do consenso, e o Executivo, com a finitude dos recursos, cada vez mais, depararam-se com a insuficiência de suas ações para atender à concretização dos direitos humanos e dos valores constitucionais.

A escassez de respostas, de um lado, e a reorganização dos campos sociais, de outro, levaram as sociedades a depositar a confiança nos sistemas de justiça como um meio de solução de todos os problemas, como bem observaram inicialmente Tate e Vallinder (1995), e tantos outros que estudam os fenômenos do ativismo judicial e da judicialização das políticas públicas'. A nova arquitetura institucional propicia o desenvolvimento de um ambiente político que viabilizou a participação ativa do Judiciário nos processos decisórios e ocupa um lugar estratégico no controle das políticas públicas. (BOCHENEK, 2013)

Assim, após lento e gradativo avanço, é possível dizer que não prevalece mais a tese de que o Judiciário não pode analisar as políticas públicas ou a falta delas, ao contrário, cada vez mais é demandado a se posicionar a respeito dos mais variados temas. O Supremo Tribunal Federal consolidou o posicionamento de ser lícito ao Poder Judiciário

$\overline{1}$ Em outro estudo, abordo o fenômeno. (BOCHENEK, 2019, p. 66-76) 
determinar que a administração pública adote medidas assecuratórias de direitos constitucionalmente reconhecidos como essenciais, sem que isso configure violação do princípio da separação dos Poderes (BRASIL, 2014). É possível, assim, que a atuação do Judiciário não seja "cegamente omissa" nem "irresponsavelmente ativista", mas que garanta os direitos fundamentais, ou seja, é lícito ao Judiciário impor à administração pública obrigação de fazer, consistente na promoção de medidas para efetivar os direitos constitucionais, não sendo oponíveis o argumento da reserva do possível e o princípio da separação dos Poderes. (BRASIL, 2016)

Há um consenso de que o Judiciário, direta ou indiretamente, analisa as políticas públicas quando aprecia as demandas que the são submetidas. Contudo, não é possível dizer o mesmo em relação aos seus limites, às suas formas, às objeções, à sua extensão e a outros pontos em debate, para definir e encontrar o equilíbrio da medida mais adequada da intervenção. Também é relevante lembrar que outros fatores externos ao processo judicial (alterações temporais, sociais, culturais) transmutam as relações jurídicas e o Judiciário. Nessa mesma linha, o juiz, ao analisar os interesses de todos os envolvidos, bem como as prioridades políticas da sociedade, sempre deve buscar o melhor resultado possível e a efetividade das decisões. Para tanto, compreender e delimitar as controvérsias das lides e as novas funções do Judiciário nas sociedades contemporâneas ${ }^{2}$, principalmente os litígios estruturantes e de alta complexidade, necessariamente exige uma postura mais aberta ao diálogo e à participação democrática cidadã e institucional, ainda que a legislação processual não contemple ferramentas específicas para tal finalidade.

Nesse sentido, a Corte da Cidadania brasileira se pronunciou para reconhecer as demandas estruturais no sistema de justiça brasileiro e o controle judicial de políticas públicas. Destaca-se o acórdão do Recurso Especial n. 1.733.412/12, voto relatado pelo Ministro Og Fernandes, julgado na sessão de 17 de setembro de 2019, pela Segunda Turma.

A referida sentença reconhece que os processos estruturais, dos quais a pretensão deve ser considerada como de alteração do estado de coisas ensejador da violação dos direitos, nos casos de soluções pontualmente as infringências legais, cuja judicialização reiterada pode resultar em intervenção até mais grave na discricionariedade administrativa que se pretende evitar ao prestigiar as ações individuais.

\footnotetext{
$\overline{2}$ Sobre as funções sociais do direito, ver Hespanha (2007, p. 133-252).
} 
Neste processo, foi afastada a decisão genérica indeferitória de impossibilidade de intervenção judicial nas falhas de prestação do serviço de saúde.

Também os ministros da Terceira Turma do STJ, no Recurso Especial n. 1.854.847/CE, relatado pela Ministra Nancy Andrighi, na sessão de 2 de junho de 2020, reconhecem os litígios de natureza estrutural e as suas principais características. Ainda, no decorrer do acórdão, consta a expressa posição de que conquanto não haja, no Brasil, a cultura e o arcabouço jurídico adequado para lidar corretamente com as ações que demandam providências estruturantes e concertadas, o voto-condutor consigna que não se pode negar a tutela jurisdicional minimamente adequada ao litígio de natureza estrutural, sendo inviável, em regra, que conflitos dessa magnitude social, política, jurídica e cultural sejam resolvidos de liminar ou antecipadamente, sem exauriente instrução e sem participação coletiva. Em outras palavras, a relatora diz que o Judiciário não pode se eximir de processar as demandas pelo simples fundamento de que o Estado não reuniria as condições necessárias para a implementação de políticas públicas e as ações destinadas à resolução ou ao menos à minimização de danos, perdas e prejuízos da não atuação do Estado ou da ineficiência ou insuficiência dela. O caso decidido teve como debate a política pública de acolhimento institucional de menores por período superior àquele estipulado pelo Estatuto da Criança e do Adolescente e as repercussões das políticas públicas envolvidas nesse caso.

Em termos amplos, sociais e jurisprudenciais, a intervenção judicial nas políticas públicas é admitida como anotada nos precedentes das cortes superiores e também é utilizada por diversos atores sociais e institucionais como uma arena de debate do espaço público democrático. Assim, para atender aos reclamos dos chamados estados de desconformidade das políticas públicas, pela via judicial, principalmente nos conflitos de alta complexidade e estruturais ${ }^{3}$, a sociedade demanda novas formas e ferramentas procedimentais adaptáveis às especificidades dos litígios envolvidos. A evolução e a transmutação das funções judiciais são desafios a serem estudados,

\footnotetext{
"Ao revés, diversas são as objeções no que diz respeito a esta atuação, sendo as principais apontadas pela doutrina e jurisprudência as seguintes: (i) vedação de ingerência do Judiciário na seara própria dos Poderes Legislativo e Executivo; (ii) inexperiência do juiz no desenvolvimento de políticas públicas, por envolver amplo conhecimento técnico; (iii) necessidade de se levar em consideração as políticas públicas já em curso; (iv) o custo da implementação das medidas; e ( $v$ ) exigência não de medidas judiciais, mas de uma mudança de paradigmas da sociedade como um todo." (ARAÚJO, 2021, p. 1146-1149)
} 
pesquisados e formatados para a nova realidade, com novos contornos, possibilidades, dimensões e limites, os quais precisam ser analisados e avaliados para que o resultado da prestação da atividade jurisdicional seja o melhor possível, e eventuais intervenções em políticas públicas sejam adequadas e efetivas. Como refere Owen Fiss (2021, p. 42-43), o juiz deve ser estratégico, com poder de formular o melhor e adequado remédio.

Todas as transformações promovidas pela evolução nos sistemas de justiça e poderes estatais revelam que o tema dos denominados litígios e processos estruturantes ainda é incipiente, mas avança a partir das decisões das cortes superiores, como anteriormente abordado, embora ainda restrito à admissão de procedimentos adaptáveis, sem maiores definições ou parâmetros para o processamento dos conflitos estruturais ${ }^{4}$. Como em regra nos novos institutos, nem os nomes, tampouco os conceitos de conflitos, demandas ou processos estruturais, gozam de uniformidade. Em linhas gerais, o processo estrutural caracteriza-se por: levar ao Judiciário um problema estrutural em estado de desconformidade; objetivar uma transição desse estado, uma reestruturação, para remover a situação de desconformidade, mediante implementação de decisões; compreender e delimitar o problema estrutural e estabelecer um programa ou projeto de reestruturação; flexibilizar as normas processuais para propor soluções, ouvir a todos os interessados, redesenhar os espaços de participação, preservar o contraditório, efetivar as deliberações consensuais e judiciais. Vitorelli (2021a, p. 332) sintetiza que litígios estruturais envolvem conflitos multipolares, alta complexidade, para promover valores públicos pela via jurisdicional, mediante a transformação de uma instituição pública ou privada. A concepção de adjudicação, apresentada por Owen Fiss (2017, p. 25), entende, de forma concisa, que é "um processo social por meio do qual os juízes dão significado aos valores públicos".

Para além dos ajustes conceituais, os operadores do direito, no ordenamento jurídico brasileiro, ainda não contam com ferramentas normativas balizadoras, ou seja, há carência legislativa quanto aos aspectos procedimentais de litígios de alta complexidade estruturantes, especialmente para atender aos casos em que as cortes determinaram

\footnotetext{
${ }^{4}$ Conceitos de conflitos, litígios, demandas, processos estruturais não são homogêneos. Para Vitorelli, uma proposta de definição perpassa pelas específicas nuances quanto à complexidade e conflituosidade, para classificar em litígio coletivo, processo coletivo, litígios estruturais, processos estruturais e processo civil de interesse público. (VITORELLI, 2021b, p. 25-92)
} 
o processamento das demandas de modo estrutural, como citado acima. Por outro lado, tramita na Câmara dos Deputados o Projeto de Lei n. 8.058/2014, com o objetivo de regulamentar o processo especial para controle e intervenção em políticas públicas pelo Poder Judiciário.

Em que pese o projeto não tratar especificamente das demandas estruturais, no texto apresentado constam ponderações, interessantes e relevantes, a respeito de um novo modelo prestacional de jurisdição que coincide em muitos aspectos com os valores e critérios das demandas estruturais. A análise detida do texto revela que é possível destacar as características, as nomenclaturas e os valores a seguir: estruturais; policêntricos; dialogais; de cognição ampla e profunda, de modo a propiciar ao juiz o assessoramento necessário ao pleno conhecimento da realidade fática e jurídica; colaborativos e participativos, flexíveis quanto ao procedimento a ser consensualmente adaptado ao caso concreto; sujeitos à informação, ao debate e ao controle social, por qualquer meio adequado, processual ou extraprocessual; tendentes às soluções consensuais, construídas e executadas de comum acordo com o Poder Público e que adotem, quando necessário, comandos judiciais abertos, flexíveis e progressivos, de modo a consentir soluções justas, equilibradas e exequíveis, na flexibilização do cumprimento das decisões; que preveem o adequado acompanhamento do cumprimento das decisões por pessoas físicas ou jurídicas, órgãos ou instituições que atuem sob a supervisão do juiz e em estreito contato com este. Salientam-se a flexibilização e as medidas de gestão procedimentais que são essenciais ao trato das demandas estruturantes e pontos de relevo no presente estudo.

Apesar de o debate legislativo não ter avançado, a prática processual revela que tal medida é cada vez mais urgente e necessária, e os juízes, por todo o país, têm adotado para os litígios estruturais e de alta complexidade, em níveis e dimensões variadas, os preceitos identificados no anteprojeto. A constatação pode ser aferida nos textos doutrinários mais recentes e nas práticas judiciais, principalmente, em primeira instância, de todo o Judiciário nacional, seja para cumprir as decisões das cortes superiores, seja para processar as demandas que afloram por todos os cantos. Nesse caminho, despontam duas características essenciais dos processos estruturais, isto é, a gestão judicial dessas demandas e a flexibilidade dos procedimentos existentes, com a aplicabilidade adaptável das normas, sobretudo, condizente com as exigências de uma atuação eficiente e atual do Poder Judiciário. 
Nesse sentido, o escopo principal da pesquisa foi extrair as melhores funcionalidades das regras processuais existentes para aplicá-las nos trilhos que direcionam a solução dos conflitos estruturais. A interpretação dos dispositivos legais é uma tarefa dos intérpretes e aplicadores do direito, com maior destaque e relevância, após o legislador privilegiar e adotar conceitos abertos e indeterminados ${ }^{5}$, especialmente para as normas processuais, que incentivam a adaptabilidade na aplicação ao caso concreto. Reafirma-se aqui que para cada demanda há um procedimento adaptável para processar e julgar o caso concreto pela via judicial.

O legislador, em que pese não normatizar os procedimentos para melhor atender às demandas estruturantes, promoveu uma série de alterações legislativas que apontam várias pistas nas linhas dos preceitos e valores acima referidos. Considerando os litígios de alta complexidade e estruturantes, com características reguladas pelo CPC bem diferentes do processo civil tradicional, é preciso destacar que, nos últimos anos, algumas reformas pontuais têm indicado transformações dos procedimentos e das formas de concretização e efetivação dos direitos materiais. Entre elas, a principal foi o Código de Processo Civil de 2015, que contém regras que impulsionaram a flexibilização e atribuíram mais poderes de gestão, para além de conferir maior espaço de atuação aos magistrados no processamento das demandas. Todavia, o modelo processual que nos trouxe até aqui para a ampliação da aplicação das ferramentas disponíveis ao magistrado não é recente. A sua positivação veio com o art. 84 do CDC, reforçada pela reforma no art. 461 do CPC, que conferiu maior espaço para o julgador adotar todas as medidas pertinentes para obter o melhor resultado para o processo, ou seja, conjuga a maior efetividade com a menor onerosidade do devedor. (OSNA, 2021, p. 486-487)

Portanto, em face da ausência de regras próprias para o manejo dos conflitos estruturais, os operadores do direito operam a relativização e a mitigação de diversos institutos tradicionais do processo civil. Ademais,

\footnotetext{
${ }^{5}$ A emergência da técnica legislativa aberta, cada vez mais justificada, pela multiplicidade de casos que necessitam de uma solução diferenciada, que não pode ser atendida pelas regras estáticas, convencionais e tradicionais (PINTO, 2021, p. 552). E ainda define que "as sctructural injunctions são decisões judiciais que implicam o envolvimento dos tribunais na determinação e implementação de políticas públicas, a fim de garantir o cumprimento da legislação vigente". (PINTO, 2021, p. 557)
} 
a regra do art. 327, § 2, do CPC, por meio de cláusula aberta, admite que o procedimento comum seja utilizado e adaptado com o emprego das técnicas processuais diferenciadas previstas nos procedimentos especiais. A doutrina entende que é uma cláusula geral de flexibilização procedimental, um "portal de trânsito de técnicas" dos procedimentos (DIDIER JR.; ZANETI JR.; OLIVEIRA, 2021), ou seja, uma espécie de livre trânsito de técnicas de gestão processual, confirmada pelo art. 1.049 do CPC. Logo, aqui há um reforço à ideia defendida de que para cada caso há um tipo de procedimento adaptado e flexível para atender melhor e com eficiência a prestação jurisdicional.

Para além da flexibilização, os tradicionais dogmas do processo civil tradicional exigem amplas reformulações e adaptações para atender às linhas gerais dos processos estruturais, em especial nos seguintes pontos: a adstrição da decisão ao pedido, pela reformulação do princípio da correlação e da congruência para possibilitar a ampliação e/ou alteração do conteúdo da demanda no decorrer do processo e alterar a vedação de limitação dos debates aos contornos da causa de pedir; a dimensão da prova, principalmente pela adoção efetiva dos meios de prova atípicos e na produção delas - art. 369 do CPC; a ampliação do direito ao recurso para atender aos reclamos de todos os potenciais afetados pela decisão e aqui também avançar nos aspectos da legitimidade da representação processual; as mutações aos limites de inalterabilidade (preclusões processuais), imutabilidade (coisa julgada) ${ }^{6}$ para novos regimes de estabilidades flexíveis às constantes mudanças sociais; o avanço na utilização de medidas executivas atípicas de cumprimento das decisões judiciais, com enfoque eficiente no resultado prático equivalente - arts. 139, IV, 297 e 536, § 1ำ do CPC, ainda por delegação de funções jurisdicionais aos auxiliares do juízo - art. 69 do CPC; a ampliação dos instrumentos de cooperação judiciária (art. 69 do CPC); a substituição efetiva do formalismo excessivo pela vontade das partes, com a ampliação das negociações jurídicas processuais (calendarização, produção de provas - arts. 190 e 191 do (PC).

\footnotetext{
${ }^{6}$ No CPC de 2015, foi normatizada a concepção de estabilidades processuais como gênero, não propriamente a coisa julgada, mas integrado por esta, ao lado de outras, como a estabilidade da tutela provisória de urgência satisfativa antecedente (art. 304), a decisão de saneamento e organização do processo (art. 357), da jurisprudência pelo sistema de precedentes (art. 926). As estabilidades estão mais próximas da compreensão objetiva de segurança jurídica enquanto "continuidade", permissividade de mudanças, redução de impactos e transições suaves, de modo a viabilizar maior racionalização de "quebras" de estabilidades. (VIANA, 2021, p. 1107-1108)
} 
Por outro lado, a abertura para relativização (flexibilização, adaptabilidade ou plasticidade) exige a redefinição da noção de contraditório (ARENHART, 2021, p. 1051-1070), forte e ampliado, para que cada parte e interessados expressem pontos de vista e atuação, com oportunidade de manifestações. Ainda, exige maior participação dos cidadãos e da sociedade nos processos judiciais, na medida em que as políticas públicas examinadas nos litígios estruturais se destinam para toda a coletividade. Assim, amplia-se o campo democrático, e os métodos participativos são identificados fortemente com as ferramentas do amicus curiae (CABRAL, 2019, p. 379-408) e audiências públicas.

Outro aspecto da relativização no sistema processual está vinculado à organização judiciária e à divisão das tarefas entre os juízes. A rigidez das normas de competência e a divisão tradicional territorial estanque mergulham em novos horizontes de flexibilização, seja pela criação de juízos especializados, equalizações de cargas de trabalho, virtualização processual, como no programa Justiça 4.0 do Conselho Nacional de Justiça. Na seara administrativa, foram intensificadas as ações das centrais e dos núcleos de apoio, entre eles podemos citar as centrais de inteligência, a rede nacional de cooperação judiciária (Resolução n. 350/2020) e os laboratórios de inovação, regulamentados pelo Conselho Nacional de Justiça. Ainda, na gestão judicial dos acervos, constam preceitos de movimentação processual ampliada com a aplicabilidade da conexão processual e a cooperação judicial, bem como foram permitidas expressamente (art. 55 do CPC) a centralização de processos e a concertação de atos processuais (arts. 67 a 69 do (PC).

Nesse sentido, a interpretação do pedido inicial, da contestação e das decisões judiciais precisa considerar o contexto e a boa-fé (arts. 322 , § 2ำ e 489, § 3ㅇa ambos do CPC), ou seja, a decisão judicial interpretada (e aplicada) a partir da conjugação de todos os seus elementos e em conformidade com o princípio da boa-fé. A peculiaridade está na não limitação do debate aos contornos da causa de pedir e na não vinculação ao exato pedido formulado pelas partes, isto é, na construção de um postulado mais genérico e abrangente. Logo, o disposto está em consonância com a complexidade das demandas estruturais e ocorre a flexibilidade da congruência objetiva e não se restringe aos postulados da interpretação inicial e da contestação, mas a todos os pontos que interferem, ainda que potencialmente, no litígio estrutural, ou seja, há uma constante adaptabilidade do objeto do litígio, como refere Marcella Ferraro (2015, p. 144, 153), ocorre uma certa plasticidade da demanda. 
Portanto, é necessária uma flexibilização procedimental a fim de tutelar o direito das partes e efetivar as políticas públicas que estão em desconformidade, por meio de um procedimento gerido e supervisionado na esfera judicial. Na medida em que os fatos são esclarecidos, os problemas e as soluções podem ser relidos e redescobertos ao longo do processo. O pedido e a decisão podem ser progressivamente adequados às alterações da realidade. Relativiza-se a estabilização da demanda (art. 329 do CPC) do processo estrutural. Nesta linha, o atual art. 493 do CPC estabelece que se, depois da propositura da ação, algum fato constitutivo, modificativo ou extintivo do direito influir no julgamento do mérito, caberá ao juiz tomá-lo em consideração, de ofício ou a requerimento da parte, no momento de proferir a decisão. Em síntese performativa, para cada processo e conflito existe um tipo de procedimento adaptável para as suas peculiaridades e particularidades.

A flexibilização procedimental também supera a dualidade conhecimento/execução (COSTA, 2016, p. 109-136), e reforça a imbricação entre eles, com decisões de conhecimento e cumprimento, a todo tempo, desde o início do processo, como a antecipação dos efeitos da tutela, até no final, com as decisões de conhecimento na fase final de cumprimento, como a liquidação e as impugnações. Nas demandas estruturais, as fases cognitivas/executivas são continuamente monitoradas e revisadas, e entrelaçadas, a depender do tipo de conflito judicializado. Portanto, há uma simbiose das fases cognitivas e executivas. O conteúdo decisional ou consensual operado pelo processo é definido em uma pluralidade de providências com o fim de alcançar mudanças estruturais, mas não necessariamente os meios para obtê-lo, na esteira da norma de cumprimento das obrigações de fazer como a prestação da tutela específica ou equivalente. A imutabilidade das decisões não é mais um mandamento, pois as ordens se adaptam às necessidades reais e se amoldam conforme a mutação do objeto ou as transformações das políticas públicas. Logo, conforme a implementação das medidas estruturantes e a observação de seus resultados, novas decisões são elaboradas, sendo possível o uso de provimentos em espiral ou teia de aranha?.

Ainda em termos legislativos, posteriormente, houve um outro avanço significativo, especialmente na Lei de Introdução às Normas do

\footnotetext{
${ }^{7}$ A metáfora de uma teia de aranha, na qual se entrelaçam as tensões dos fios, de tal forma que o aumento das tensões sobre um dos fios exige uma redistribuição das tensões entre todos os demais, a fim de se garantir que a teia se conserve. (FULLER; WINSTON, 1978, p. 395)
} 
Direito Brasileiro - LINDB (Lei n. 13.655/2018) (HOHMANN; COELHO, 2O2O, p. 305-340), com detalhamentos de comandos a serem observados e aplicados pelos juízes e administradores no exercício das suas atividades. As novas normas alteram que frontalmente o processo civil, antes tão somente restrito ao modelo adversarial, bipolar, retrospectivo, formal, rígido, para então atender com eficiência outros tipos de conflitos com características: multipolares, policêntricas, multifocais, com função performativa, efeitos prospectivos e pervasivos. Esses conflitos estruturais exigem que os processos e os procedimentos se desenvolvam por meio de diálogo, consenso e ampla participação democrática, observem os valores das políticas públicas existentes e os preceitos de transição e medidas executivas tomadas para as ações de governo. Aqui, o legislador buscou também a tendência de estabilidade enquanto continuidade (art. 23) para determinar que, nas decisões dos processos administrativos e judiciais, haja previsão de "regime de transição", nas hipóteses de interpretação ou orientação nova sobre norma de conteúdo indeterminado ou de imposição de novo dever ou condicionamento do direito, ou seja, ocorreu reforço dos preceitos das estabilidades dinâmicas e flexíveis, sintonizadas a efetividade e conformação do processo à realidade social, em contraponto à rigidez procedimental e em atenção às transformações sociais. Houve ainda avanço na adoção de práticas administrativas que incentivam e promovem os valores consensuais, como sinal relevante de que a administração pública pode e deve, em determinados casos, inclusive judiciais, valer-se desses expedientes para atingir o melhor resultado possível, mesmo que suas ações dependam também das soluções advindas de controvérsias judicializadas ${ }^{8}$. As práticas consensuais apresentam as vantagens de gerar nos cidadãos

\footnotetext{
${ }^{8} \mathrm{O}$ legislador ampliou os meios e as práticas de soluções consensuais, entre eles: Termo de Ajustamento de Conduta - TAC da Lei n. 7.347/1985 (arts. 5ำ e 6); a Lei de Introdução ao Direito Brasileiro, art. 26 (Lei n. 13.655/2018); a Lei n. 12.529/2011 - Lei de Defesa da Concorrência; a arbitragem nos contratos de parceria público-privada (art. 11, III, Lei n. 11.079/2005); contratos de concessão (art. 23-A da Lei n. 8.987/1995); na administração pública (Lei n. 13.129/2015); o CPC ampliou as formas de conciliação e mediação (arts. 165 e 174); a Lei da Mediação (Lei n. 13.140/2015); o Regime diferenciado de contratação da Lei n. 13.190/2015; Termo de Ajustamento de Gestão - TAG do art. 26 da LINDB; os acordos substitutivos e compromissos processuais do art. 27 da LINDB; a Lei n. 13.867/2019 da mediação e arbitragem para definir valor de desapropriação por utilidade pública; Portaria n. 320/2019 - Núcleo Especializado em Arbitragem NEA; Decreto n. 9.830/2019 - compromisso para evitar ACPs; Decreto n. 9.957/2019 regulamenta a Relicitação (Lei n. 13.448/2017); Decreto n. 10.025/2019 - arbitragem entre Administração e setor portuário e de transportes; Lei n. 12.594, de 18 de janeiro de 2012 (Sistema Nacional de Atendimento Socioeducativo) no art. 35, 11 - excepcionalidade da intervenção judicial e da imposição de medidas, favorecendo-se meios de autocomposição de conflitos.
} 
(partes interessadas) a sensação de confiabilidade, credibilidade e boa-fé na administração, por meio da efetiva participação das partes envolvidas.

Após um panorama da flexibilização processual adaptada às demandas estruturais, é possível reforçar a conclusão de que não há apenas um ou poucos modelos de procedimentos para o Judiciário utilizar nas suas atividades, ao contrário, haverá tantos modelos quanto os tipos de conflitos de interesses submetidos ao Judiciário, ou seja, para cada processo, um tipo de procedimento adaptável e flexível às próprias características do conflito de interesses. Por outro lado, não é crível exigir dos legisladores a normatização de todos os estilos possíveis de procedimentos, tampouco eles conseguiriam levantar ou imaginar todas as hipóteses de conflitos decorrentes da riqueza das experiências sociais diárias. Para superar as carências e as ausências, uma solução foi criar normas processuais, com conceitos abertos e adaptáveis, para o intérprete e aplicador, principalmente para o magistrado fazer a gestão dos procedimentos nas demandas que recebem para processar e julgar (art. 327 do CPC). Outro fator a reforçar a tese aqui desenvolvida reside na prescrição normativa de que o Judiciário não pode se furtar de apresentar uma resposta às demandas que lhe são submetidas, como as cortes brasileiras têm manifestado, inclusive em relação aos processos estruturantes.

Nesse cenário de complexidade das relações sociais, aumenta, proporcionalmente, a tendência de normas de processo civil mais abertas e amplas, e ao magistrado, condutor e impulsionador do processo, e às partes, provocadoras e fiscalizadoras dos atos, cabe a missão de corresponder, com as suas respectivas participações no processo, de modo a atuar em grau máximo de cooperação e colaboração, além de utilizar a flexibilização, a adaptabilidade e a plasticidade processual. Neste ponto, reside a relevância das demandas estruturais serem ajuizadas com o máximo de elementos para que o magistrado utilize os preceitos normativos processuais flexibilizados na instrução do caso concreto, com resultados positivos melhores em termos de efetividade da prestação jurisdicional.

Os postulados estão à mesa e permitem uma atuação adaptável, por parte dos operadores do sistema de justiça, quanto aos tipos de conflito e litígios submetidos ao Judiciário. Assim, aos juízes, em face da função condutora e impulsionadora da demanda, são acrescentadas novas atribuições para aplicar as melhores técnicas de gestão, processual e administrativa, moldadas para cada conflito estrutural. 
A academia produziu grande número de estudos e teses quanto à viabilidade e às vantagens da aplicação dos princípios do processo estrutural no sistema judicial brasileiro, com referências à origem americana - Brown $\times$ Board of Education (BAUERMANN, 2021, p. 305328; PUGA, 2021, p. 91-146), reforma do sistema prisional do Arkansas (VIOLIN, 2021, p. 637-686) e casos de repercussão em outros países, como o estado de coisas inconstitucionais da experiência da Colômbia (MARÇAL, 2021, p. 45-56; DANTAS, 2019, p. 123-178). Contudo, ainda são esparsos os estudos empíricos de casos brasileiros de demandas estruturais, enquanto há vários estudos teóricos que procuram identificar as suas principais características. Neste sentido, também são incipientes os contornos da sistematização ou definição dos procedimentos e ritos aplicados nos casos práticos no ordenamento jurídico nacional. Estas ausências dificultam o trabalho, tanto dos procuradores quanto dos magistrados, no que diz respeito à adoção de procedimentos a serem aplicados aos casos em face das especificidades e peculiaridades das demandas estruturais. Entretanto, isto não impede, aliás recomenda, o avanço de estudos e pesquisas para identificar as coincidências, as vantagens e as desvantagens, os limites ou as possibilidades de aplicar um método ou outra técnica.

$\mathrm{Na}$ linha investigativa deste texto, para além da interpretação e aplicação flexível das normas processuais, as demandas estruturais revelam, como anotado anteriormente, um espaço amplo para a gestão judicial das demandas e o gerenciamento dos ritos procedimentais. Um processo estrutural exige raciocínio diferenciado do juiz, ou seja, para efetivar os direitos envolvidos nos conflitos estruturais, o magistrado se obriga a tomar decisões que demandam postura mais ativa e, muitas vezes, assume uma função semelhante à de um gestor público, tanto no quesito operacional quanto estratégico9.

Para iniciar, quando receber uma demanda, é essencial ao juiz compreender (conhecer todos os desdobramentos possíveis do curso do processo e de todos os efeitos das decisões) e delimitar a demanda estrutural para ampliar ou restringir o âmbito de atuação judicial. Para tanto, é fundamental a ampla participação dos envolvidos e interessados, bem como é necessário constante diálogo judicial e institucional. Este gerenciamento é um elemento propulsor para a construção de soluções

\footnotetext{
${ }^{9} \mathrm{~A}$ autora desenvolve estudo para compreender de que forma a teoria da racionalidade limitada pode se aplicar à tomada de decisão em processos estruturais. Aponta que a função do juiz é semelhante a de um administrador e o processo é construído continuamente por meio de negociações e debates. (ROSA, 2021, p. 1222)
} 
consensuais para resolver todas as controvérsias, ou parte delas, de um litígio estrutural. As ferramentas mais utilizadas para esse desiderato são os encontros, as reuniões, as vistorias (tradicionalmente chamadas de audiências e inspeções) para que as partes e principalmente os juízes, conheçam os conflitos e a extensão deles, para além de detalhar quais pontos podem ser melhor trabalhados, seja na via consensual ou por outros meios de construção coletiva da decisão judicial.

Ainda, a cláusula geral para a realização de negócios jurídicos processuais fortalece a crescente valorização da vontade dos sujeitos do processo (autonomia privada e consensualidade) e apresenta potencial significativo para moldar as ferramentas que podem interferir diretamente na gestão das demandas, com prestígio a autocomposição (arts. 3오 § 2ํ․ e $3^{\circ}$ do CPC), os atos cooperativos (arts. 5 e 6ㅇ) , a arbitragem (art. 31 da Lei n. 9.307/1996), além dos negócios jurídicos processuais típicos: cláusula de eleição de foro, calendário processual, renúncia ao prazo, acordo da suspensão do processo, organização consensual do processo, adiamento negociado da audiência, convenção a respeito do ônus da prova, escolha consensual do perito, para além da cláusula expressa de negociações atípicas do art. 190 do CPC (GISMONDI; RODRIGUES, 2021, p. 782). Em suma, uma flexibilização procedimental voluntária pela organização processual comparticipada, cooperada e consensual (convencionalidade), cujos resultados processuais efetivos serão melhores se forem bem utilizados, principalmente pela participação colaborativa da gestão judicial, essencialmente necessária para a gestão dos processos estruturais.

Também a cooperação judiciária (arts. 67 a 69 do CPC) é fundamental para a gestão judicial das demandas estruturais, principalmente para a eficiência da prestação jurisdicional, tanto na perspectiva endoprocessual (gestão dos processos) quanto macroprocessual (administração judiciária) (LAMÊGO, 2021, p. 492). Há várias possibilidades de cooperação, como: o auxílio direto entre juízes, a reunião ou o apensamento de processos conexos ou correlatos, a prestação de informações dos diversos órgãos, os atos concertados entre os juízes cooperantes (estes para a prática de citação, intimação ou notificação de ato, a obtenção e apresentação de provas e a coleta de depoimentos); as medidas para a efetivação de tutela provisória; a efetivação de medidas e providências para recuperação e preservação de empresas; a facilitação de habilitação de créditos na falência e na recuperação judicial; a centralização de processos repetitivos para a produção de prova, instrução processual e julgamento; a execução de 
decisão jurisdicional, também a ampliação dos conceitos e hipóteses de conexão de processos ou probatória, a possibilidade de centralização de demandas individuais.

Não há uma solução única ou fórmulas mágicas para melhorar a gestão dos litígios estruturais. Contudo, em face das novas funções de coordenação das atividades, alguns pontos são verificados nos processos estruturais quanto à participação efetiva, ativa e cooperativa do juiz gestor: líder na construção de soluções conjuntas, atuações e decisões estratégicas, supera o velho dogma da inércia; gestor público e gestor do processo; agente transformador de mudanças sociais significativas.

A complexidade e a conflituosidade policêntrica exigem do juiz novas técnicas para articular e gerir o tempo do processo, em outros termos, antecipar ou postergar o exame de determinados pontos, a considerar estrategicamente o momento oportuno, além de contar com a comparticipação, em variadas dimensões, institucionais e privadas, de sujeitos externos (PEREIRA; VOGT, 2021, p. 392). Este é um terreno fértil para novas pesquisas e experiências.

As opções estudadas neste artigo quanto à flexibilização procedimental e à gestão judicial e processual não são exaustivas, mas revelam pistas que podem ser utilizadas em novas pesquisas e investigações, para posteriores análises e confrontos, no processo dialógico de construção de conhecimentos e da evolução dos institutos jurídicos. Nesse sentido, os apontamentos de elementos de flexibilização e gestão dos procedimentos das demandas estruturais são fundamentais para nortear os estudos, mas principalmente para orientar os magistrados nas conduções dos processos, em especial daqueles que afetam as políticas públicas em estado de desconformidade quando forem submetidas à apreciação do Judiciário. Além disso, o impacto dos estudos propiciou efeitos prospectivos para o avanço do debate legislativo a respeito do tema.

Dentro de campo preambular de análise do estágio atual do processo civil brasileiro, a doutrina e as legislações processuais brasileiras estiveram conectadas aos estágios metodológicos do direito processual civil: sincretismo ou imanentismo, autonomismo ou processualismo, instrumentalismo e neoprocessualismo ou formalismovalorativo, explicam os caminhos adotados pela ciência do direito processual (ATAÍDE JÚNIOR, 2017). O neoprocessualismo, atual estágio metodológico em construção, inspira grande parte do CPC e coincide em alguns pontos com os aspectos dos processos estruturais, pois o 
processo é revisto a partir dos princípios constitucionais e direitos e garantias fundamentais, assim como é reestruturado de acordo com o direito constitucional. A cooperação intersubjetiva é ainda a matriz do direito constitucional processual, ou seja, nem a ação (porque privilegia as partes) nem a jurisdição (porque privilegia o juiz) podem estar no centro metodológico. Após analisar os estágios metodológicos, o autor conclui que as soluções processuais são dominadas pelo paradigma racionalista e sugere que é o momento de pensar a construção de um novo estágio metodológico para o processo, mais empirista e pragmático, que leve a sério as experiências para superar, em um futuro próximo, as insuficiências do atual modelo racionalista.

Tanto no campo dogmático como no jurisprudencial, foram identificados pontos de sinergia e convergência quanto à necessidade de analisar e avaliar as práticas e as experiências, para atender às demandas estruturais que estão na linha de tendências e de construção de um novo modelo metodológico do processo civil. O experimentalismo processual analisado sob as perspectivas de estudo empírico, como no mestrado profissional da Escola Nacional de Formação e Aperfeiçoamento de Magistrados - Enfam, apresenta potenciais elevados para contribuir com o novo modelo a ser construído e esperado para atender demandas e conflitos antes sufocados pelo paradigma racionalista.

Para além das ferramentas processuais e outras que possam ser legisladas, todas de aplicação relevante, no contexto de análise empirista e pragmática, que leve a sério as experiências e as práticas, amplia-se a observância dos planejamentos, das estratégias, aplicações, execuções e dos gerenciamentos dos processos realizados pelos juízes e provocados pelas partes, sempre com o objetivo de oferecer a melhor efetividade da prestação jurisdicional. Este fenômeno pode ser denominado de gestão judicial eficiente e ocorre sob dois níveis de enfoque: um administrativo e outro judicial, sempre entrelaçando e observando os princípios e valores públicos constitucionais e os direitos humanos. (NEGRI, 2019, p. 46-98)

As bases fundamentais decorrentes das teorias processuais acima sintetizadas foram aplicadas a esta pesquisa, com enfoque no processo estrutural. Os resultados são aportes teóricos e práticos de ferramentas efetivas que podem ser utilizadas para alguns tipos de demandas estruturantes, públicas e privadas (MARTINS-COSTA; SILVA, 2020), aplicadas por meio da plasticidade, adaptabilidade e flexibilidade 
de normas processuais, bem como pelos métodos e técnicas de gestão processual e judicial10.

Após a sintetização de todas as novas ideias a respeito dos conflitos, demandas e processos estruturais, bem como a viabilidade operacional da movimentação de aparatos estatais e privados, é preciso considerar que é muito importante avaliar a efetividade prática das decisões proferidas nos processos estruturais, ou seja, se elas foram úteis, promoveram mudanças sociais concretas e positivas e de que maneira as transformações aconteceram. Assim, o que esperar dessas ações e o tempo necessário entre as decisões judiciais e o início das transformações? $\bigcirc$ tempo e o espaço aqui são limitados, mas essas indagações integram o objeto de estudo da disciplina Demandas estruturais e litígios de alta complexidade pertencente ao programa de mestrado da Enfam, que tem por objetivo investigar e pesquisar vários casos práticos e as suas efetividades, mas também as oportunidades desperdiçadas, com a intenção de relacionar alguns esboços com pistas e dicas relevantes para a construção de medidas prescritivas em torno de circunstâncias, elementos e fatores que contribuem para um nível mínimo de teorização dos processos e das decisões estruturais, especialmente a respeito dos instrumentos processuais dispostos aos operadores do direito e de boas práticas de gestão judicial, em face de que a matéria é relativamente nova no cenário jurídico e processual brasileiro.

O programa de mestrado da Enfam e muitos juízes brasileiros têm contribuido significativamente para essas transformações, sobretudo para recompor o espaço público e superar a insuficiência da cisão tradicional entre público e privado, ampliar a moldura do sistema de resolução de litígios restrita ao binômio lícito e ilícito. Isso significa que a função jurisdicional se altera, tanto em sua estrutura quanto em sua função, para redesenhar a capacidade de atuação do magistrado no processo, pela intervenção continuada, propositiva, pervasiva, sempre em constante fiscalização e ajuste, por meio de maior abertura dialógica para obtenção de consensos e correção de rumos. (OSNA, 2021, p. 468470)

\footnotetext{
10 Sobre gestão judicial, na obra ora referenciada, foram abordadas diferentes perspectivas de gestão judicial, tanto no Brasil como na Europa. (BOCHENEK; FREITAS; COELHO; LOPEZ; MATOS; MENDES, 2018)
} 
Uma nota relevante neste estágio de avanço da aplicabilidade dos conceitos estruturais, um ponto fulcral, é o equilíbrio entre eventuais excessos e equívocos que possam resultar na autofagia desses sistemas, por um lado, e nas alternativas concretas de transformações sociais e na aplicação de políticas públicas, por intermédio de processos judiciais, por outro lado. Em suma, o equilíbrio entre as potencialidades e as armadilhas, porventura, decorrentes de institutos em formação e o reconhecimento pelos tribunais, principalmente as cortes superiores brasileiras.

Por fim, há muitas fronteiras a serem ultrapassadas para que os processos estruturais sejam implementados com excelência, especialmente quanto aos aspectos de flexibilidade e gestão processual e judicial, como foi apontado neste texto. Contudo, os primeiros passos foram dados e cabe aos pesquisadores explorarem os campos abertos para traduzir as experiências em práticas e teorias para serem utilizadas pelos operadores dos direitos, legisladores e principalmente para nortear as autoridades e os representantes do governo com poderes para implementar políticas públicas em benefício de toda a coletividade. 


\section{REFERÊNCIAS}

ARAÚJO, Vanessa Mascarenhas. A sentença estruturante e o pleno acesso à justiça: em busca adequada da solução dos litígios coletivos complexos e da efetividade das políticas públicas. In: ARENHART, Sérgio Cruz; JOBIM, Marco Félix. Processos estruturais. 3. ed. Salvador: JusPodivm, 2021. p. 1135-1160.

ARENHART, Sérgio Cruz. Processos estruturais no direito brasileiro: reflexões a partir do caso da ACP do carvão. In: ARENHART, Sérgio Cruz; JOBIM, Marco Félix. Processos estruturais. 3. ed. Salvador: JusPodivm, 2021. p. 1047-1070.

ATAÍDE JÚNIOR, Vicente de Paula. Os estágios metodológicos do direito processual civil. In: CAZZARO, Kleber. Estudos de direito processual civil à luz da Constituição Federal. Erechim: Deviant, 2017.

BAUERMANN, Desirê. Structural injunctions no direito norte-americano. In: ARENHART, Sérgio Cruz; JOBIM, Marco Félix. Processos estruturais. 3. ed. Salvador: JusPodivm, 2021. p. 305-328.

BOCHENEK, Antônio César. A interação entre tribunais e democracia por meio do acesso aos direitos e à justiça: análise de experiências dos juizados especiais federais cíveis brasileiros. 1. ed. Brasília: Conselho da Justiça Federal, 2013. v. 1, 561 p.

BOCHENEK, Antônio César. Interação entre tribunais e democracia: concepções de acesso aos direitos e à justiça. 1. ed. Curitiba: Juruá. 2019.

BOCHENEK, Antônio César; FREITAS, Vladimir Passos; COELHO, Nuno; LOPEZ, José Mouraz; MATOS, José Igreja; MENDES, Luis Azevedo.

Manual luso-brasileiro de gestão judicial. 1. ed. São Paulo: Almedina, 2018. v. 1. 406 p.

BRASIL. Câmara dos Deputados. Projeto de Lei n. 8.058/14. Institui processo especial para o controle e intervenção em políticas públicas pelo Poder Judiciário e dá outras providências. Brasília: Câmara dos Deputados, 2014a. Disponível em: https://www.camara.leg.br/ proposicoesWeb/fichadetramitacao?idProposicao=687758. Acesso em: 24 maio 2021. 
BRASIL. Conselho Nacional de Justiça. Resolução n. 350, de 27 de outubro de 2020. Estabelece diretrizes e procedimentos sobre a cooperação judiciária nacional entre os órgãos do Poder Judiciário e outras instituições e entidades, e dá outras providências. Brasília, DF: Conselho Nacional de Justiça, 2020a. Disponível em: https://atos.cnj. jus.br/files/original182611202011035falaOc3a36f6.pdf. Acesso em: 14 abr. 2021.

\section{BRASIL. [Constituição (1988)]. Constituição da República Federativa}

do Brasil de 1988. Brasília, DF: Presidência da República, [2020]. Disponível em: http://www.planalto.gov.br/ccivil_03/constituicao/ constituicao.htm. Acesso em: 14 abr. 2021.

BRASIL. Lei n. 8.080, de 19 de setembro de 1990. Dispõe sobre as condições para a promoção, proteção e recuperação da saúde, a organização e o funcionamento dos serviços correspondentes e dá outras providências. Brasília, DF: Presidência da República, 1990. Disponível em: http://www.planalto.gov.br/ccivil_03/leis//8080.htm. Acesso em: 14 abr. 2021.

BRASIL. Lei n. 9.307, de 23 de setembro de 1996. Dispõe sobre a arbitragem. Brasília, DF: Presidência da República, 1996. Disponível em: http://www.planalto.gov.br/ccivil_03/leis/I9307.htm. Acesso em: 14 abr. 2021.

BRASIL. Lei n. 13.105, de 16 de março de 2015. Código de Processo Civil. Brasília, DF: Presidência da República, 2015a. Disponível em: 2011http://www.planalto.gov.br/ccivil_03/_ato2015-2018/2015/lei//13105. htm. Acesso em: 14 abr. 2021

BRASIL. Lei n. 13.655, de 25 de abril de 2018. Inclui no Decreto-Lei n. 4.657, de 4 de setembro de 1942 (Lei de Introdução às Normas do Direito Brasileiro), disposições sobre segurança jurídica e eficiência na criação e na aplicação do direito público. Brasília, DF: Presidência da República, 2018. Disponível em: http://www.planalto.gov.br/ccivil_03/_ Ato2015-2018/2018/Lei/L13655.htm\#art1. Acesso em: 14 abr. 2021.

BRASIL. Superior Tribunal de Justiça. (2. Turma). Recurso Especial n. 1.733.412/SP. Recorrente: Ministério Público do Estado de São Paulo. Recorrido: Hospital Municipal Professor Alipio Correa Netto - Ermelino Matarazzo e Município de São Paulo. Relalor: Min. Og Fernandes, 17 de setembro de 2019. Disponível em: https://scon.stj.jus. br/SCON/GetInteiroTeorDoAcordao?num_registro=201702412530\&dt_ publicacao=20/09/2019. Acesso em: 24 maio 2021. 
BRASIL. Superior Tribunal de Justiça. (3. Turma). Recurso Especial n. 1.854.847/CE. Recorrente: Ministério Público do Estado do Ceará. Recorrido: Municipio de Fortaleza. Relator: Min. Nancy Andrighi, O2 de junho de 2020b. Disponível em: https://scon.stj.jus.br/SCON/ GetInteiroTeorDoAcordao?num_registro=201901607463\&dt_ publicacao=04/06/2020. Acesso em: 24 maio 2021.

BRASIL. Supremo Tribunal Federal. (1. Turma). Agravo Regimental em Agravo de Instrumento n. 739.151/PI. Agravante: Estado do Piauí. Agravado: Ministério Publico do Estado do Piauí. Relator: Min. Rosa Weber, 27 de maio de 2014b. DJe 11.06.2014. Disponível em: http:// portal.stf.jus.br/processos/downloadPeca.asp?id=233607256\&ext=.pdf. Acesso em: 24 maio 2021.

BRASIL. Supremo Tribunal Federal. (Tribunal Pleno). Recurso Extraordinário n. 592.581-RS. Repercussão geral. Recurso do MPE contra Acórdão do TJRS. Reforma de sentença que determinava a execução de obras na Casa do Albergado de Uruguaiana. Recorrente: Ministério Público do Estado do Rio Grande do Sul. Recorrido: Estado do Rio Grande do Sul. Relator: Min. Ricardo Lewandowski, 13 de Agosto de 2015b. DJe, 1 fev. 2016. Disponível em: http://portal.stf.jus.br/ processos/detalhe.asp?incidente=2637302. Acesso em: 24 maio 2021.

CABRAL, Antonio do Passo. O amicus curiae no novo Código de processo civil. In: SICA, Heitor; CABRAL, Antonio; ZANETI JR., Hermes (org.). Temas de direito processual contemporâneo. 1. ed. Serra: Milfontes, 2019. v. 1, p. 379-408.

COSTA, Eduardo José da Fonseca. A "execução negociada" de políticas públicas em Juízo. Revista do Ministério Público do Rio de Janeiro, Rio de Janeiro n. 59, p. 109-136, jan./mar. 2016.

\section{DANTAS, Eduardo Sousa. Ações estruturais e o estado de coisas} inconstitucional: a tutela dos direitos fundamentais em casos de graves violações pelo poder público. Curitiba: Juruá. 2019. 249 p.

DIDIER JR. Fredie, ZANETI JR., Hermes; OLIVEIRA, Rafael Alexandria. Elementos para uma teoria do processo estrutural aplicada ao processo civil brasileiro. In: ARENHART, Sérgio Cruz; JOBIM, Marco Félix.

Processos estruturais. 3. ed. Salvador: JusPodivm, 2021. p. 423-462. 
FERRARO, Marcella Pereira. Do processo bipolar a um processo coletivo-estrutural. 2015. Dissertação (Mestrado) - Universidade Federal do Paraná (UFPR), Curitiba, 2015.

FISS, Owen. As formas de justiça. In: FISS, Owen. Direito como razão pública: processo, jurisdição e sociedade. Coordenação da Tradução: Carlos Alberto de Salles. 2. ed. Curitiba: Juruá, 2017. p. 25.

FISS, Owen. To make the constitution a living truth. Four lectures on the structural injunction. In: ARENHART, Sérgio Cruz; JOBIM, Marco Félix.

Processos estruturais. 3. ed. Salvador: JusPodivm, 2021. p. 31-56.

FULLER, Lon L.; WINSTON, Kenneth I. The Forms and Limits of Adjudication. Harvard Law Review, [S./.], v. 92, n.2, Dec. 1978.

GISMONDI, Rodrigo; RODRIGUES, Marco Antonio. Negócios jurídicos processuais como mecanismos de auxílio à efetivação de políticas públicas. In: ARENHART, Sérgio Cruz; JOBIM, Marco Félix. Processos estruturais. 3. ed. Salvador: JusPodivm, 2021. p. 779-814.

HESPANHA, António Manuel. O caleidoscópio do direito: o direito e a justiça nos dias e no mundo de hoje. Coimbra: Almedina, 2007.

HOHMANN, Ana Carolina; COELHO, Fernanda. As alterações da LINDB e as novas perspectivas do controle da administração pública. Revista de Direito Administrativo e Infraestrutura, Regulação e Compliance, São Paulo, v. 14, n. 14, p. 305-340, jul/set. 2020.

KATYAL, Neal K. Judges as advicegivers. Stanford Law Review, [S./.], v. 50, 1998.

LAMÊGO, Gustavo Cavalcanti. Técnicas de cooperação judiciária nacional aplicadas a processos estruturais. In: ARENHART, Sérgio Cruz; JOBIM, Marco Félix. Processos estruturais. 3. ed. Salvador: JusPodivm, 2021. p. 491-518.

MARÇAL, Felipe Barreto. Processos estruturantes. Salvador: JusPodivm. 2021.

MARTINS-COSTA, Judith Martins; SILVA, Paula Costa e. Crise e perturbações no cumprimento da prestação: estudo de direito comparado luso-brasileiro. São Paulo: Quartier Latin, 2020. 368 p. 
NEGRI, Sandra. A produção de valores públicos de gestão no Poder Judiciário brasileiro sob a ótica da Teoria de Moore. 2019. Tese (Doutorado em Administração) - Programa de Pós-Graduação em Administração da Universidade Nove de Julho (UNINOVE), São Paulo, 2019.

OSNA, Gustavo. Nem "TUDO", nem "NADA": decisões estruturais e efeitos jurisdicionais complexos. In: ARENHART, Sérgio Cruz; JOBIM, Marco Félix. Processos estruturais. 3. ed. Salvador: JusPodivm, 2021. p. 463-490.

PEREIRA, Lara Dourado Mapurunga; VOGT, Fernanda Costa. Novas técnicas decisórias nos processos estruturais. In: ARENHART, Sérgio Cruz; JOBIM, Marco Félix. Processos estruturais. 3. ed. Salvador: JusPodivm, 2021. p. 385-408.

PINTO, Henrique Alves. A condução de decisões estruturais pelo Código de processo civil de 2015: breve análise teórica e pragmática. In: ARENHART, Sérgio Cruz; JOBIM, Marco Félix. Processos estruturais. 3. ed. Salvador: JusPodivm, 2021. p. 519-558.

PUGA, Mariela. La Litis Estructural en el caso BROWN V. BOARD of education. In: ARENHART, Sérgio Cruz; JOBIM, Marco Félix. Processos estruturais. 3. ed. Salvador: JusPodivm, 2021. p. 91-146.

ROSA, Viviane Lemes da. Aplicações da teoria da racionalidade limitada às decisões estruturais. In: ARENHART, Sérgio Cruz; JOBIM, Marco Félix. Processos estruturais. 3. ed. Salvador: JusPodivm, 2021. p. 1221-1245.

RUSHIN, Stephen. Competing Case Studies of Structural Reform Litigation in American Police Departments. Ohio State Law Journal of Criminal Law, [S.I.], v. 14, p. 113-141, 2016.

SABEL, Charles F.; SIMON, Wilian H. Destabilization rights: how public law litigation succeeds. Haward Law Review, [S.I.], v. 117, n.4, p. 1015-1101, Feb. 2004.

TATE, C. Neal; VALLINDER, Torbjörn. The global expansion of judicial power. London: New York University Press, 1995.

VIANA, Thaís Costa Teixeira. Os processos estruturais entre a máxima do interesse público e o paradigma de flexibilidade processual: reflexões sobre o contraste à luz do regime das estabilidades. In: ARENHART, 
Sérgio Cruz; JOBIM, Marco Félix. Processos estruturais. 3. ed. Salvador: JusPodivm, 2021. p. 1097-1116.

VIOLIN, Jordão. Holt V. Sarver e a reforma do sistema prisional no Arkansas. In: ARENHART, Sérgio Cruz; JOBIM, Marco Félix. Processos estruturais. 3. ed. Salvador: JusPodivm, 2021. p. 637-686.

VITORELLI, Edilson. Litígios estruturais: Decisão e implementação de mudanças socialmente relevantes pela via processual. In: ARENHART, Sérgio Cruz; JOBIM, Marco Félix. Processos estruturais. 3. ed. Salvador: JusPodivm, 2021a. p. 329-383.

VITORELLI, Edilson. Processo civil estrutural. 2. ed. Salvador: JusPodivm, 2021b. 